\title{
Profile Matching untuk Menentukan Besaran Kenaikan Gaji Karyawan pada PT. Eka Mandiri Sukses
}

\author{
David $^{1}$, Marfuah ${ }^{2}$ \\ 1 Universitas Universal, Fakultas Komputer, Program Studi Sistem Informasi \\ 2 Universitas Universal, Fakultas Komputer, Program Studi Sistem Informasi
}

\begin{abstract}
Every company wants the best and maximum results in every production process. To achieve the best results in the production process/company activities, it is necessary to have support from every aspect of the company such as employees, supporting facilities, etc. One of the efforts to improve employee performance is support from the company in the form of salary increases. In the process of determining/considering an increase in employee salaries in the company, there are several obstacles or problems that will be encountered/faced by the company, including time efficiency, calculating employee performance, and the number of employee data files that must be processed. Decision Support System is a system to support material decision makers / makers in terms of semi-structural decisions. The profile matching method is a method for solving a problem so as to rank the best candidates from predetermined criteria. This study uses several criteria in decision making including work attitude, personality and responsibility, Based on 3 employee data, the final result is A01 and A02 getting a 5\% increase in basic salary while A03 is 4\%. and the results of this study is to use the Profile Matching method to find out the ranking or value weights in the assessment of the best employees, in the results of this study it helps in making decisions more quickly and accurately and the results can be accounted for. This research aims to be able to help PT. Eka Mandiri Success in determining employee salary increases
\end{abstract}

Keywords: Decision Support System; Profile Matching Method

corresponding email : davidisen00@gmail.com

This is an open access article under the CC BY license

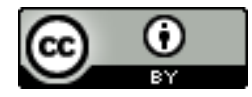

\section{INTRODUCTION}

Teknologi informasi terus berkembang pesat [1]. Hal tersebut menjadikan teknologi informasi sangat berpengaruh pada aktivitas sehari-hari dalam kehidupan manusia menjadi lebih mudah, cepat dan akurat. Informasi adalah salah suatu hal penting yang harus diperhatikan dan sering kali dijadikan landasan dalam pengambilan keputusan oleh pimpinan. Tanpa informasi, sebuah perusahaan tidak dapat menjalankan operasional dengan baik. Sehingga manusia berupaya untuk mengembangkan sistem yang terkomputerisasi supaya kegiatan operasional lebih efektif dan efesien. Setiap perusahaan pasti menginginkan hasil terbaik dan maksimal dalam setiap proses produksi. Untuk mencapati hasil terbaik dalam proses kegiatan perusahaan perlu adanya dukungan dari setiap aspek-aspek perusahaan seperti karyawan, sarana pendukung, dll. Salah satu usaha untuk meningkatkan kinerja karyawan adalah dukungan dari perusahaan berupa kenaikan gaji. Proses penentuan kenaikan gaji karyawan di perusahaan terdapat beberapa kendala atau masalah yang akan dihadapi oleh perusahaan antara lain efesiensi waktu, perhitungan performa karyawan, dan banyaknya berkas data karyawan yang harus diolah. Sistem Pendukung Keputusan adalah sebuah sistem untuk mendukung para pemegang keputusan material dalam hal keputusan-keputusan yang bersifat semi-struktural. PT. Eka Mandiri Sukses adalah perusahaan yang bergereka di bidang pengiriman dan logistic berada di kota Batam, Manajemen karyawan PT. Eka Mandiri Sukses berjumlah 310. Pihak HRD dari PT. Eka Mandiri Sukses memiliki kendala dalam proses menentukan gaji karyawan berdasarkan performa kerja para karyawan yang dimiliki. Dalam penentuan gaji karyawan PT. Eka Mandiri Sukses menggunakan beberapa kriteria diantaranya Pemahan terhadap kerjaan, kedisiplinan tanggung jawab selama kerja. Metode profile matching adalah adalah suatu metode untuk memecahkan suatu masalah sehingga memberikan 
perangkingan kepada kandidat terbaik dari kriteria - kriteria yang telah ditentukan. Tujuan penelitian ini adalah untuk membantu HRD perusahaan dalam manajemen SDM untuk menentukan besaran kenaikan gaji karyawan. Metode profile matching berdasarkan penelitian sebelumnya [2] digunakan untuk menentukan pemberian reword terhadap para karyawan pada PT. Atlas Jakarta, hasil dari penelitian ini yaitu dengan menggunakan metode profile matching mengatasi penilaian yang subjektif dalam menentukan pemberian reword terhadap karyawan.

\section{LITERATURE REVIEW}

Penelitian yang dilakukan oleh Edi Suhartono pada tahun 2021 menggunakan metode profile matching untuk penunjang keputusan terhadap seleksi pegawai baru. Permasalahan yang dihadapi dalam penelitian ini yaitu banyak nya jumlah pelamar calon pegawai baru yang lolos seleksi namun tidak sesuai dengan yang di dibutuhkan perusahaan. Hal ini dipengaruhi dengan adanya pemberian nilai yang subjektif. Dengan demikian dilakukan suatu kajian dengan penggunaan suatu metode profile matching dalam sistem pendukung keputusan dalam penentuan seleksi penerimaan calon karyawan baru. Penelitian ini mendapakan hasil bahwa dalam proses seleksi menggunakan metode profile matching menjadi lebih cepat dan tepat [3].

Penelitian yang dilakukan oleh Dedi Saputra pada tahun 2021 menggunakan metode profile matching untuk penunjang keputusan memberikan penghargaan Pelanggan. Permasalahan yang dihadapi dalam penelitian ini yaitu kesulitan dalam menentukan pelanggan utama pada PT. Pengiriman Atlaslayanan, karena jumlah pelanggan yang banyak dan belum terkomputerisasi.Dengan demikian dilakukan suatu kajian dengan penggunaan suatu metode profile matching dalam sistem pendukung keputusan dalam penentuan penghargaan hingga yang terbaik. Penelitian ini mendapakan hasil bahwa sistem pendukung keputusan menggunakan metode Profile Matching dapat digunakan dalam memilih yang pelanggan terbaik untuk manajemen perusahaan dalam memutuskan pelanggan mana yang akan diberikan penghargaan[2].

Penelitian yang dilakukan oleh Firdaus Idam pada tahun 2019 menggunakan metode profile matching untuk pemilihan karyawan terbaik pada PT. Surindo Murni Agung. Permasalahan yang dihadapi dalam penelitian ini yaitu proses penilaian kinerja karyawan di PT. Surindo Murni Agung masih belum ada sehingga tidak bisa menentukan karyawan terbaik. Dengan demikian dilakukan suatu kajian dengan penggunaan suatu metode profile matching dalam sistem pendukung keputusan untuk melakukan pemilihan karyawan terbaik pada PT. Surindo Murni Agung. Penelitian ini mendapakan hasil bahwa sistem pendukung keputusan menggunakan metode Profile Matching dengan beberapa aspek Kriteria yaitu: sikap kerja,kepribadian dan tanggung jawab, pengambilankeputusan menjadi lebih cepat dan akurat serta dapat diperbandingkan hasilnya[4].

Penelitian yang dilakukan oleh Aditya Sudarmadi pada tahun 2017 menggunakan metode profile matching untuk penunjang keputusan terhadap pemilihan personal homeband UniversitasBrawijaya. Permasalahan yang dihadapi dalam penelitian ini yaitu tidak ada nya mekanisme penilaian yang jelas dalam proses penilaian calon personel, Seleksi personel yang terdahuluhanya menentukan aspek yang dinilai dalam seleksi, namun tidak memiliki mekanisme apa yang jelas. Dengan demikian dilakukan suatu kajian dengan penggunaan suatu metode profile matching dalam sistem pendukung keputusan terhadap pemilihan personal homeband UniversitasBrawijaya.Penelitian ini mendapakan hasil bahwa sistem pendukung keputusan menggunakan metode Profile Matching berhasil di implementasikan terhadap home band Universitas Brawijaya[5].

Penelitian yang dilakukan oleh Frieyadie pada tahun 2016 menggunakan metode profile matching untuk penunjang keputusan kenaikan jabatan pada instansi pemerintah. Permasalahan yang dihadapi dalam penelitian ini yaitu masih adanya pemeringkatan secara sepihak menimbulkan kecemburuan sosial danpenilaian menjadi objektif, masih belum ada penilaian yang efektif membuat penilaian hanya berdasarkankriteria tertentu.Dengan demikian dilakukan suatu kajian dengan penggunaan suatu metode profile matching dalam sistem pendukung keputusan kenaikan jabatan pada instansi pemerintah. Penelitian ini mendapakan hasil bahwa sistem pendukung keputusan menggunakan metode Profile Matching dapat membantu Instansi khusunya untuk menentukan beberapa masalah khususnya mengenai kenaikan jabatan[6].

\section{RESEARCH METHOD}

Profile matching merupakan salah satu metode pengambilan keputusan yang digunakan dalam manajemen SDM dengan melakukan perbandingan GAP antara nilai alternatif dan kriteria [7][8]. Adapun tahapan dalam metode profile matching sebagaimana figure 1. 


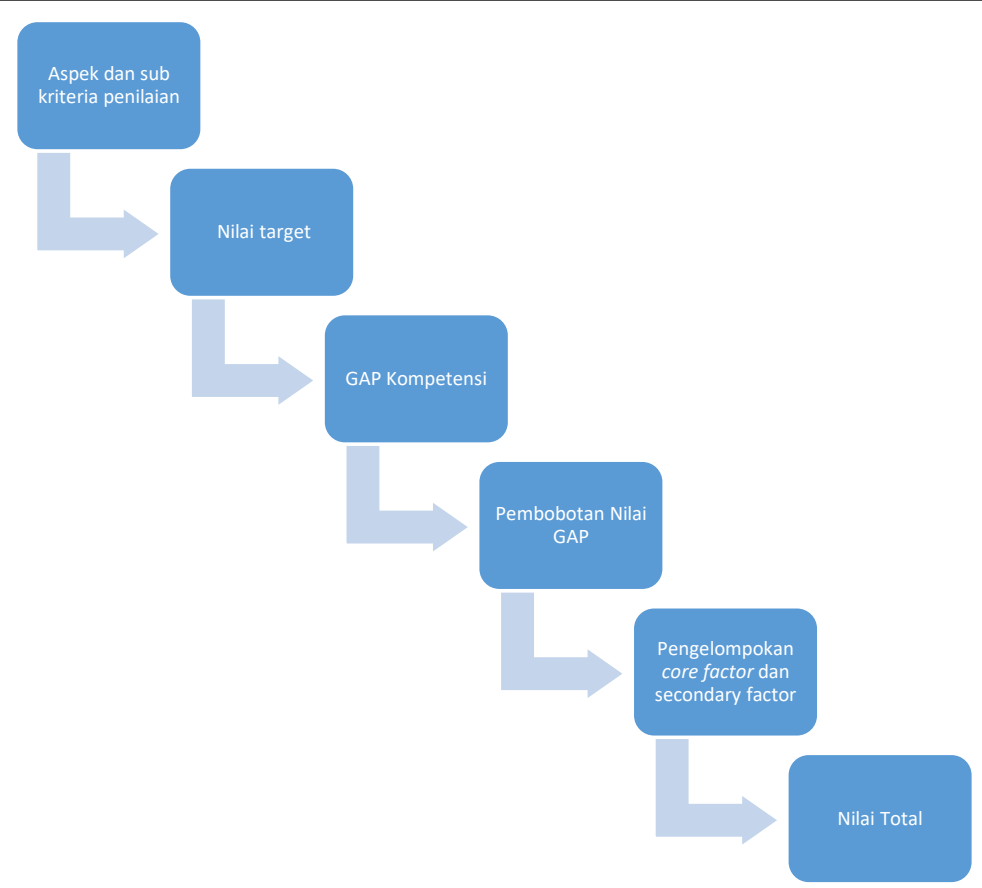

Figure 1. Tahapan Profile Matching [2]

Berdasarkan figure 1 dalam menentukan besaran kenaikan gaji karyawan, terdapat beberapa kriteria yang digunakan dalam penelitian ini, sebagaimana table 1 .

Table 1. Kriteria

\begin{tabular}{clc}
\hline Kode & \multicolumn{1}{c}{ Kriteria } & Profile \\
\hline P001 & Pemahaman terhadap kerjaan & 4 \\
P002 & Kedisiplinan & 3 \\
P003 & Sikap Kerja & 2 \\
P004 & Tanggung Jawab Selama Kerja & 4 \\
P005 & Status Karyawan & 2 \\
P006 & Akademik & 3 \\
\hline
\end{tabular}

Setelah menentukan kriteria penilaian, selanjutnya yaitu menentukan nilai variabel untuk setiap aspek kriteria penilaian. Nilai variabel yang telah ditentukan kemudian akan dihitung dengan pemetaan GAP, hal ini dilakukan untuk menghitung selisih dari masing-masing aspek dengan value target. Nilai variabel untuk setiap kriteria sebagaimana table 2 .

Table 2. Nilai Variabel

\begin{tabular}{|c|c|c|c|c|}
\hline Kode & $\begin{array}{c}\text { Nama } \\
\text { Kriteria }\end{array}$ & Profil & Himpunan & Variabel \\
\hline \multirow{4}{*}{ P001 } & \multirow{4}{*}{ Pemahaman } & \multirow{4}{*}{4} & Nilai $>=85$ & 4 \\
\hline & & & Nilai >-70 - <85 & 3 \\
\hline & & & Nilai $>=55-<70$ & 2 \\
\hline & & & Nilai $<55$ & 1 \\
\hline \multirow{4}{*}{ P002 } & \multirow{4}{*}{ Kedisiplinan } & \multirow{4}{*}{3} & $>=95 \%$ & 4 \\
\hline & & & $>=90 \%-<95 \%$ & 3 \\
\hline & & & $>=85 \%-<90 \%$ & 2 \\
\hline & & & $<85 \%$ & 1 \\
\hline \multirow{4}{*}{ P003 } & \multirow{4}{*}{ Sikap Kerja } & \multirow{4}{*}{2} & Nilai $>=85$ & 4 \\
\hline & & & Nilai $>-70-<85$ & 3 \\
\hline & & & Nilai $>=55-<70$ & 2 \\
\hline & & & Nilai $<55$ & 1 \\
\hline
\end{tabular}


JAST : Journal of Applied Science and Technology

Volume. 02 Number. 01, January 2022

ISSN : 2775-4022

http://jurnal.unissula.ac.id/index.php/JAST

\begin{tabular}{|c|c|c|c|c|}
\hline \multirow{4}{*}{ P004 } & \multirow{4}{*}{$\begin{array}{l}\text { Tanggung } \\
\text { Jawab }\end{array}$} & \multirow{4}{*}{3} & Nilai $>=85$ & 4 \\
\hline & & & Nilai $>-70-<85$ & 3 \\
\hline & & & Nilai $>=55-<70$ & 2 \\
\hline & & & Nilai $<55$ & 1 \\
\hline \multirow{4}{*}{ P005 } & \multirow{4}{*}{$\begin{array}{l}\text { Status } \\
\text { Karyawan }\end{array}$} & \multirow{4}{*}{2} & Menikah, Anak > 2 & 4 \\
\hline & & & Menikah, Anak $=<2$ & 3 \\
\hline & & & Menikah, Anak 0 & 2 \\
\hline & & & Belum Menikah & 1 \\
\hline \multirow{4}{*}{ P006 } & \multirow{4}{*}{ Akademik } & \multirow{4}{*}{3} & $>\mathrm{S} 1$ & 4 \\
\hline & & & D1-D3 & 3 \\
\hline & & & SMA & 2 \\
\hline & & & SMP & 1 \\
\hline
\end{tabular}

Kemudian dilakukan proses untuk menentukan GAP kompetensi dari selisih antara nilai kriteria terhadap nilai target menggunakan persamaan (1).

$$
\text { GAP = value attribute }- \text { value target }
$$

dan pembobotan terhadap nilai GAP. Setelah itu melakukan pengkelompokan kriteria kedalam 2 kelompok yaitu core factor dan secondary factor. Berdasarkan pengelompokan kemudian dilakukan perhitungan nilai total berdasarkan persentase dari nilai core factor dan secondary factor. Rumus perhitingan nilai total dapat diperoleh erdasarkan persamaan (2)[9].

$$
\mathrm{NT}=60 \% \mathrm{NCF}+40 \% \mathrm{NSF}
$$

Keterangan :

$\mathrm{NCF}=$ Nilai Core Factor

$\mathrm{NSF}=$ Nilai Secondary Factor

NT = Nilai total dari penjumlahan

$(\mathrm{x}) \%=$ Nilai persen yang dimasukkan

Tahap selanjutnya yaitu penentuan ranking. Perhitungan ini menggunakan rumus sebagaimana persamaan (3).

$$
\text { Rangking }=(\mathrm{x}) \% \mathrm{Nk}+(\mathrm{y}) \% \mathrm{~N}
$$

Keterangan :

$\mathrm{Nk} \quad=$ Nilai aspek status

Ns =Nilai persen yang diinputkan $(70 \%, 30 \%)$ 3.

Hasil dari perengkingan dapat menentukan besaran kenaikan gaji karyawan dengan menggunakan acuan table

Table 3. Besaran Kenaikan Gaji

\begin{tabular}{ll}
\hline \multicolumn{1}{c}{ Nilai Total } & Besaran kenaikan gaji \\
\hline$>=4.5$ & $5 \%$ dari gaji pokok \\
$<4.5->=4$ & $4 \%$ dari gaji pokok \\
$<4->=3$ & $3 \%$ dari gaji pokok \\
$<3$ & $2 \%$ dari gaji pokok \\
\hline
\end{tabular}

\section{RESULT AND ANALYSIST}

Pada penelitian ini dilakukan terhadap 3 orang sample data karyawan PT. Eka Mandiri Sukses untuk menentukan besaran kenaikan gaji karyawan. Pemetaan GAP Kompetensi yang digunakan untuk menghitung selisih masing-masing aspek dengan value target sebagaimana table 4. 
JAST : Journal of Applied Science and Technology

Volume. 02 Number. 01, January 2022

ISSN : 2775-4022

http://jurnal.unissula.ac.id/index.php/JAST

Table 4. GAP Kompetensi

\begin{tabular}{|c|c|c|c|c|}
\hline Kode & $\begin{array}{c}\text { Nama } \\
\text { Karyawan }\end{array}$ & Kriteria & Himpunan & Variabel \\
\hline \multirow[t]{6}{*}{ A01 } & Vivian & Pemahaman terhadap job desk & Nilai $>=85$ & 4 \\
\hline & & Kedisiplinan & $>=90 \%-<95 \%$ & 3 \\
\hline & & Sikap Kerja & Nilai $>-70-<85$ & 3 \\
\hline & & Tanggung Jawab Kerja & Nilai $>=85$ & 4 \\
\hline & & Status Karyawan & Belum Menikah & 1 \\
\hline & & Akademik & SMA & 2 \\
\hline \multirow[t]{6}{*}{$\mathrm{A} 02$} & Rinny & Pemahaman terhadap job desk & Nilai $>-70-<85$ & 3 \\
\hline & & Kedisiplinan & $>=90 \%-<95 \%$ & 3 \\
\hline & & Sikap Kerja & Nilai $>-70-<85$ & 3 \\
\hline & & Tanggung Jawab Kerja & Nilai $>=85$ & 4 \\
\hline & & Status Karyawan & $\begin{array}{l}\text { Menikah, Anak } \\
0\end{array}$ & 2 \\
\hline & & Akademik & SMA & 2 \\
\hline \multirow[t]{6}{*}{ A03 } & Doni & Pemahaman terhadap job desk & Nilai $>=85$ & 4 \\
\hline & & Kedisiplinan & $>=95 \%$ & 4 \\
\hline & & Sikap Kerja & $\begin{array}{l}\text { Nilai }>=55- \\
<70\end{array}$ & 2 \\
\hline & & Tanggung Jawab Kerja & Nilai $>-70-<85$ & 3 \\
\hline & & Status Karyawan & $\begin{array}{l}\text { Menikah, Anak } \\
>2\end{array}$ & 4 \\
\hline & & Akademik & D1- D3 & 3 \\
\hline
\end{tabular}

Selanjutnya menentukan selisihnya dengan pemetaan GAP. Pemeteaan GAP aspek performa karyawan sebagaimana table 5 dan pemetaan GAP aspek status sebagaimana table 6.

Table 5. Pemetaan GAP Aspek Performa Karyawan

\begin{tabular}{lllll}
\hline \multirow{2}{*}{ Alternatif } & \multicolumn{4}{c}{ Value } \\
\cline { 2 - 5 } & P001 & P002 & P003 & P004 \\
\hline A01 & 4 & 3 & 3 & 4 \\
A02 & 3 & 3 & 3 & 4 \\
A03 & 4 & 4 & 2 & 3 \\
\hline Profile & 4 & 3 & 2 & 4 \\
\hline A01 & 0 & 0 & +1 & 0 \\
A02 & -1 & 0 & +1 & 0 \\
A03 & 0 & +1 & 0 & -1 \\
\hline
\end{tabular}

Table 6. Pemetaan GAP Aspek Status

\begin{tabular}{lll}
\hline \multirow{2}{*}{ Alternatif } & \multicolumn{2}{c}{ Value } \\
\cline { 2 - 3 } & P005 & P006 \\
\hline A01 & 4 & 3 \\
A02 & 2 & 2 \\
A03 & 1 & 2 \\
\hline Profile & 2 & 3 \\
\hline A01 & 2 & 0 \\
A02 & 0 & -1 \\
A03 & -1 & -1 \\
\hline
\end{tabular}

Setelah memperoleh nilai GAP pada masing-masing alternative, setiap profile alternative diberi bobot nilai sesuai ketentuan pada tabel nilai GAP. Pembobotan aspek performa karyawan sebagaimana table 7 . 
JAST : Journal of Applied Science and Technology

Volume. 02 Number. 01, January 2022

ISSN : 2775-4022

http://jurnal.unissula.ac.id/index.php/JAST

Table 7. Pembobotan Aspek Performa Karyawan

\begin{tabular}{lll}
\hline Selisih & \multicolumn{1}{c}{ Bobot Nilai } & \multicolumn{1}{c}{ Keterangan } \\
\hline 0 & 5 & Kompetensi sesuai standar \\
1 & 4.5 & Kompetensi kelebihan satu level \\
-1 & 4 & Kompetensi kekurangan satu level \\
2 & 3.5 & Kompetensi kelebihan dua level \\
-2 & 3 & Kompetensi kekurangan dua level \\
3 & 2.5 & Kompetensi kelebihan tiga level \\
-3 & 2 & Kompetensi kekurangan tiga level \\
4 & 1.5 & Kompetensi kelebihan empat level \\
-4 & 1 & Kompetensi kekurangan empat level \\
\hline
\end{tabular}

Dari pemeteaan GAP pada table 7, pembobotan nilai Gap sebagaimana tabel 8 dan pembobotan aspek status table 9.

Table 8. Pembobotan Nilai GAP

\begin{tabular}{lcccc}
\hline Alternatif & P001 & P002 & P003 & P004 \\
\hline A01 & 0 & 0 & +1 & 0 \\
A02 & -1 & 0 & +1 & 0 \\
A03 & 0 & +1 & 0 & -1 \\
\hline Nilai Bobot & & & & \\
\hline A01 & 5 & 5 & 4.5 & 5 \\
A02 & 4 & 5 & 4.5 & 5 \\
A03 & 5 & 4.5 & 5 & 4 \\
\hline
\end{tabular}

Table 9. Pembobotan Aspek Status

\begin{tabular}{lll}
\hline Selisih & Bobot Nilai & \multicolumn{1}{c}{ Keterangan } \\
\hline 0 & 5 & Kompetensi sesuai standar \\
1 & 4.5 & Kompetensi kelebihan satu level \\
-1 & 4 & Kompetensi kekurangan satu level \\
2 & 3.5 & Kompetensi kelebihan dua level \\
-2 & 3 & Kompetensi kekurangan dua level \\
3 & 2.5 & Kompetensi kelebihan tiga level \\
-3 & 2 & Kompetensi kekurangan tiga level \\
4 & 1.5 & Kompetensi kelebihan empat level \\
-4 & 1 & Kompetensi kekurangan empat level \\
\hline
\end{tabular}

Dari pemeteaan GAP pada table tersebut maka, pembobotan nilai Gap sebagaimana table 10.

Table 10. Pembobotan Nilai GAP

\begin{tabular}{lcc}
\hline Alternatif & P005 & P006 \\
\hline A01 & 2 & 0 \\
A02 & 0 & -1 \\
A03 & -1 & -1 \\
\hline Nilai Bobot & & \\
\hline A01 & 3.5 & 5 \\
A02 & 5 & 4 \\
A03 & 4 & 4 \\
\hline
\end{tabular}

Langkah selanjutnya yaitu melakukan perhitungan dan pengelompokan core factor dan secondary factor. Sebagaimana terlihat pada table 11 dan 12.

Table 11. Pengelompokan Aspek Performa Karyawan

\begin{tabular}{lllllllll}
\hline Alternatif & P001 & P002 & P003 & P004 & $\begin{array}{c}\text { Core } \\
\text { Factor }\end{array}$ & $\begin{array}{c}\text { Core } \\
\text { Factor }\end{array}$ & $\begin{array}{c}\text { Secondary } \\
\text { Factor }\end{array}$ & $\begin{array}{c}\text { Secondary } \\
\text { Factor }\end{array}$ \\
\hline A01 & 5 & 5 & 4.5 & 5 & 5 & 5 & 5 & 4.5 \\
A02 & 4 & 5 & 4.5 & 5 & 5 & 5 & 4 & 4.5 \\
A03 & 5 & 4.5 & 5 & 4 & 4.5 & 4 & 5 & 5 \\
\hline
\end{tabular}


JAST : Journal of Applied Science and Technology

Volume. 02 Number. 01, January 2022

ISSN : 2775-4022

http://jurnal.unissula.ac.id/index.php/JAST

Table 12. Pengelompokan Aspek Status Karyawan

\begin{tabular}{lllll}
\hline Alternatif & P005 & P006 & $\begin{array}{c}\text { Core } \\
\text { Factor }\end{array}$ & $\begin{array}{c}\text { Secondary } \\
\text { Factor }\end{array}$ \\
\hline A01 & 3.5 & 5 & 5 & 3.5 \\
A02 & 5 & 4 & 4 & 5 \\
A03 & 4 & 4 & 4 & 4 \\
\hline
\end{tabular}

Tahapan berikutnya yaitu menghitung nilai total, sebagaimana terlihat pada table 13 dan 14 .

Table 13. Nilai Total Aspek Performa Karyawan

\begin{tabular}{llll}
\hline Alternatif & $\begin{array}{c}\text { Core } \\
\text { Factor }\end{array}$ & $\begin{array}{c}\text { Secondary } \\
\text { Factor }\end{array}$ & $\begin{array}{c}\text { Nilai } \\
\text { Total }\end{array}$ \\
\hline A01 & 5 & 4.75 & 4.9 \\
A02 & 5 & 4.25 & 4.7 \\
A03 & 4.25 & 5 & 4.55 \\
\hline
\end{tabular}

Table 14. Nilai Total Aspek Status Karyawan

\begin{tabular}{llll}
\hline Alternatif & $\begin{array}{c}\text { Core } \\
\text { Factor }\end{array}$ & $\begin{array}{c}\text { Secondary } \\
\text { Factor }\end{array}$ & $\begin{array}{c}\text { Nilai } \\
\text { Total }\end{array}$ \\
\hline A01 & 5 & 3.5 & 4.4 \\
A02 & 4 & 5 & 4.4 \\
A03 & 4 & 4 & 4 \\
\hline
\end{tabular}

Tahapan terakhir yaitu melakukan perhitungan rangking tiap aspek, sebagaimana table 15.

Table 15. Perhitungan Ranking

\begin{tabular}{llll}
\hline Alternatif & \multicolumn{1}{c}{ Nk } & Ns & Total \\
\hline A01 & 4.9 & 4.4 & 4.75 \\
A02 & 4.7 & 4.4 & 4.61 \\
A03 & 4.55 & 4 & 4.385 \\
\hline
\end{tabular}

Erdasarkan table 15, didapatkan hasil dari perangkingan karyawan berdasarkan aspek performa dan status, sehingga diperoleh berapa persen besaran kenaikan gaji karyawan untuk besaran kenaikan gaji karyawan dapat dilihat pada table 16.

Table 16. Besaran Kenaikan Gaji Karyawan

\begin{tabular}{lll}
\hline Alternatif & $\begin{array}{c}\text { Nilai } \\
\text { Total }\end{array}$ & Besaran Kenaikan Gaji \\
\hline A01 & 4.75 & 5\% dari gaji pokok \\
A02 & 4.61 & 5\% dari gaji pokok \\
A03 & 4.385 & 4\% dari gaji pokok \\
\hline
\end{tabular}

\section{CONCLUSION}

Berdasarkan pembahasan penentuan kenaikan gaji karyawan menggunakan metode profile matching pada PT. Eka Mandiri Sukses dapat disimpulkan bahwa penggunaan metode profile matching menghindari pengambilan keputusan yang subjektif karena setiap karyawan dilakukan perhitungan nilai berdasarkan kriteria yang digunakan, hal ini memberikan hasil yang lebih baik dalam pengambilan keputusan.

\section{REFERENCES}

[1] R. Nurzianti, "Revolusi Lembaga Keuangan Syariah Dalam Teknologi Dan Kolaborasi Fintech,” J. Inov. Penelit., vol. 2, no. 1, p. 37, 2021.

[2] D. Saputra, F. Akbar, Lisnawanty, Martias, and A. Rahman, "Decision Support System For Providing Customer Reward Using Profile Matching Method," Comput. Sci. Electr. Eng., vol. 2, no. 1, pp. 28-37, 2021, doi: 10.25008/bcsee.v2i1.1142.

[3] M. B. Edi Suhartono, "Penerapan Metode Profile Matching Untuk Menunjang Keputusan Seleksi Pegawai Baru," J. PROSISKO, vol. 8, no. 1, 2021.

[4] F. Idam, A. Junaidi, and P. Handayani, "Pemilihan Karyawan Terbaik Menggunakan Metode Profile Matching Pada PT. Surindo Murni Agung,” J. Infortech, vol. 1, no. 1, pp. 21-27, 2019, doi: 10.31294/infortech.v1i1.6985.

[5] A. Sudarmadi, Edy Santoso, and Sutrisno, "Sistem Pendukung Keputusan Pemilihan Personel Homeband Universitas 
JAST : Journal of Applied Science and Technology

Volume. 02 Number. 01, January 2022

ISSN : 2775-4022

http://jurnal.unissula.ac.id/index.php/JAST

Brawijaya Menggunakan Metode Profile Matching," J. Pengemb. Teknol. Inf. dan Ilmu Komput., vol. 1, no. 12, pp. 1788-1796, 2017, [Online]. Available: www.j-ptiik.ub.ac.id.

[6] F. Frieyadie, "Penggunaan Metode Profile Matching Untuk Sistem Penunjang Keputusan Kenaikan Jabatan Pada Instansi Pemerintah," Paradig. - J. Komput. dan Inform., vol. 18, no. 2, pp. 75-80, 2016, [Online]. Available: http://ejournal.bsi.ac.id/ejurnal/index.php/paradigma/article/view/1228.

[7] S. H. Latif, L. A., Jamil , M., \& Abbas, Buku Ajar Sistem Pendukung Keputusan Teori dan Implementasi. Yogyakarta: CV Budi Utama, 2018.

[8] F. Sari, Metode dalam Pengambilan Keputusan. Yogyakarta: Deepublish, 2018.

[9] Defiariany, "Sistem Pendukung Keputusan Pemilihan Mahasiswa Berprestasi Menggunakan Metode Profile Matching Pada Stmik Indonesia Padang," J. Teknol. Inf. Pendidik., vol. 9, no. 1, pp. 153-162, 2016. 